J. Clin. Chem. Clin. Biochem.

Vol. 24, 1986, pp. $571-575$

(C) 1986 Walter de Gruyter \& Co. Berlin - New York

\title{
Enzymic Clearing of Lipaemic Serum Following Total Parenteral Nutrition: Determination of Neonatal Bilirubin as a Model
}

By A. Sharma, J. D. Artiss, D. R. Strandbergh and B. Zak

Department of Pathology, Wayne State University School of Medicine and Detroit Receiving Hospital/University Health Center, Detroit, MI, USA

(Received December 13, 1985/March 13, 1986)

Summary: Bilirubin determinations in the newborn infant are one of the many analytical tests that can yield misleading results when the specimen is either iatrogenically or naturally lipaemic. Incorporation of a recently reported enzymic clarification system into a commercially available test kit enables one to conveniently and accurately quantify both total and direct bilirubin within the present procedural characteristics of the Bilirubin Stat Analyser Photometer. This instrument measures the former directly with bichromatic spectrophotometry and the latter with a conventional diazo-type reaction. The proposed modification of existing reagents allows one to apply the assay to samples with as much as, and possibly more than $16 \mathrm{~g} / \mathrm{l}$ of triglycerides which has been introduced into the vascular circulation as intravenous total parenteral nutrition.

Enzymatische Klärung von lipaemischem Serum nach totaler parenteraler Ernährung: Bestimmung von Bilirubin bei Neugeborenen als Modell

Zusammenfassung: Bilirubinbestimmungen bei Neugeborenen gehören zu den vielen analytischen Tests, die irreführende Resultate ergeben können, wenn die Probe entweder iatrogen oder von Natur aus lipaemisch ist. Die Einbeziehung eines kürzlich beschriebenen enżymatischen Klärungsverfahrens in ein käuflich erhältliches Teštbesteck ermöglicht die bequeme und richtige quantitative Bestimmung von gesamtem und direktem Bilirubin im Rahmen der vorgegebenen Verfahrenscharakteristik des Bilirubin Stat Analyser Photometers. Dieses Gerät mißt das gesamte Bilirubin direkt mit bichromatischer Spektrophotometrie und das direkte Bilirubin mit einer konventionellen Diazoreaktion. Die vorgeschlagene Modifikation der vorhandenen Reagenzien erlaubt die Anwendung des Verfahrens auf Proben mit $16 \mathrm{~g} / 1$ oder möglicherweise mehr Triglyceriden, die als intravenöse totale parentale Ėrnährung in den Kreislauf eingebracht wurden.

\section{Introduction}

The development of intravenous total parenteral nutrition therapy for both neonatal and adult patients has led to a corresponding increase in the number of artifactually lipaemic specimens received by the clinical laboratory. However, a number of methods have been reported to be influenced adversely by the presence of this nutritive fat emulsion in blood serum $(1-3)$. One important spectrophotometric assay performed in pediatric laboratories that is seriously af- fected by the triglyceride-laden plasma is the quantification of bilirubin in the newborn infant. Previous reports have shown that the commonly used spectrophotometric measurements of bilirubin such as the diazo reaction and direct spectrophotometry are affected by the injection of Intralipid emulsion into the vascular system where it is mixed into the plasma $(4-6)$. The estimation of bilirubin in lipaemic sera, by the diazo method has been reported to be variable and therefore unreliable (6) while spurious results are 
also obtained using bichromatic spectrophotometry $(4-6)$. The present study shows how this problem of bilirubin measurement in lipaemic infant plasma can easily be overcome by using a clarification procedure similar to one reported recently for whole blood haemoglobin (7) and serum glucose (8) but modified somewhat in nonesterified fatty acid scavenging properties. This modification was necessary because of the displacement of bilirubin from its binding sites on albumin by nonesterified fatty acids, resulting in spectral changes that diminished accuracy in the measurements.

Another obstacle encountered in adapting the previously reported technique to neonatal bilirubin determinations was the large sample to reagent ratio, relative to earlier reports $(7,8)$, which meant dealing with a correspondingly larger amount of triglyceride in the reaction mixture. In addition, because of the photoreactivity of bilirubin and because this was an off-line process, it seemed reasonable to keep the clarification time as short as possible.

\section{Materials and Methods}

Lipase (from chromobacterium viscosum; glycerolester hydrolase; EC 3.1.1.3) was obtained from Finnsugar Biochemicals, Inc. (Elk Grove Village, IL). Bovine serum albumin and $\alpha-$ cyclodextrin were obtained from Sigma Chemical Company (St. Louis, MO). Intravenous fat emulsion (10\% Intralipid) was obtained from Cutter Medical, Miles Laboratories, Inc. (Berkely, CA). Bilirubin standards were obtained from American Monitor Corporation (Indianapolis, IN).

Total and direct bilirubin quantitation was carried out using Advanced Instruments Bilirubin Test Kits and the Bilirubin Stat Analyser Photometer, Model BR II (Advanced Instruments, Inc., Needham Heights, MA) ${ }^{1}$ ).

Spectral tracings were obtained using a Model 25 Spectrophotometer (Beckman Instruments, Fullerton, CA).

The enzymic-clarification reagent was prepared to contain $\mathbf{4 0 0 0}$ $\mathrm{kU}$ lipase, $4.0 \mathrm{~g}$ of $\alpha$-cyclodextrin and $20 \mathrm{~g}$ of bovine serum albumin in one liter of $5.0 \mathrm{mmol} / 1 \mathrm{Na}_{2} \mathrm{HPO}_{4}$ buffer. This reagent has a final $\mathrm{pH}$ of $8.0 \pm 0.2$ and is stable for at least three weeks when stored at $4{ }^{\circ} \mathrm{C}$.

Total bilirubin was measured by setting the instrument to the 'TOTAL' mode. One $\mathrm{ml}$ of the enzymic-clarification reagent was added to a cuvet which was used to zero the instrument. The sample $(30 \mu \mathrm{l})$ was then added to the cuvet and mixed. The total bilirubin was read after a 3 minute incubation at room temperature. Note that there is a considerable margin of safety here as the clearing process requires only $1-2$ minutes. The direct bilirubin was subsequently assayed as per manufacturer's instructions. Instrument calibration was performed using commercial bilirubin standards.

1) The instrument was loaned to us by Advanced Instruments, Inc. in order to allow us to perform the study.

\section{Results and Discussion}

The Bilirubin Stat Analyzer is a dual wavelength, narrow-bandpass photometer that measures total bilirubin bichromatically at $454 \mathrm{~nm}$ and $540 \mathrm{~nm}$. These wavelengths are chosen to measure bilirubin while correcting for oxyhaemoglobin contamination as the latter absorbs similarly at both wavelengths. However, the nature of the spectrum of turbidity causes the absorbance at $454 \mathrm{~nm}$ to be more distorted than at $540 \mathrm{~nm}$, thus making such a correction inadequate. There have been several reports to this effect $(4-6)$; however, there have been no quick, simple and inexpensive solutions.

Direct bilirubin can be measured on the same specimen with a 2-minute timed modification of the Malloy-Evelyn method (9). Erroneous direct bilirubin results have also been reported for lipaemic samples with this diazo reaction (6).

The use of enzymic clarification of the plasma of lipaemic whole blood for haemoglobin determination and serum for glucose was recently reported $(7,8)$. The same principle was used in the present investigation to clarify lipaemic neonatal serums for the bilirubin assays. The saline solution recommended by the manufacturer was replaced by the enzymic clarification reagent that contained both lipase and the free fatty acid scavanger, $\alpha$-cyclodextrin. Clarification of Intralipid-spiked human-based bilirubin standards by the enzyme clearing reagent, containing only lipase and the cyclodextrin, resulted in distortion of the bilirubin spectrum obtained after the enzymic-hydrolysis of the Intralipid. This effect is shown in figure 1. The spectrum of the bilirubin standard (bilirubin concentration $=243 \mu \mathrm{mol} / \mathrm{l}$ ) is shown as 'Bilirubin, pure standard' while the Intralipid-spiked standard (bilirubin concentration $=243 \mu \mathrm{mol} / \mathrm{l}$; Intralipid $=$ $12 \mathrm{~g} / \mathrm{l})$ is represented by the grossly distorted and mostly off-scale curve, 'Bilirubin + Triglycerides'. Clarification of this simulated lipaemic sample by the enzymic-cyclodextrin reagent yielded the spectrum "Bilirubin + Triglycerides, clarified" in which an apparent hypsochromic shift in the peak from 465 $\mathrm{nm}$ to $445 \mathrm{~nm}$ is shown, together with a slightly depressed peak absorbance. A more severe spectral aberration may be obtained with samples containing higher triglyceride concentrations. A plausible explanation for this effect may be the displacement of bilirubin from its binding sites on albumin by the large amounts of free fatty acids released during hydrolysis of the Intralipid triglyceride. This phenomenon is well known $(10-13)$ and the in-vitro displacement of bilirubin from albumin has been reported to occur when the free fatty acids/albumin concentra- 


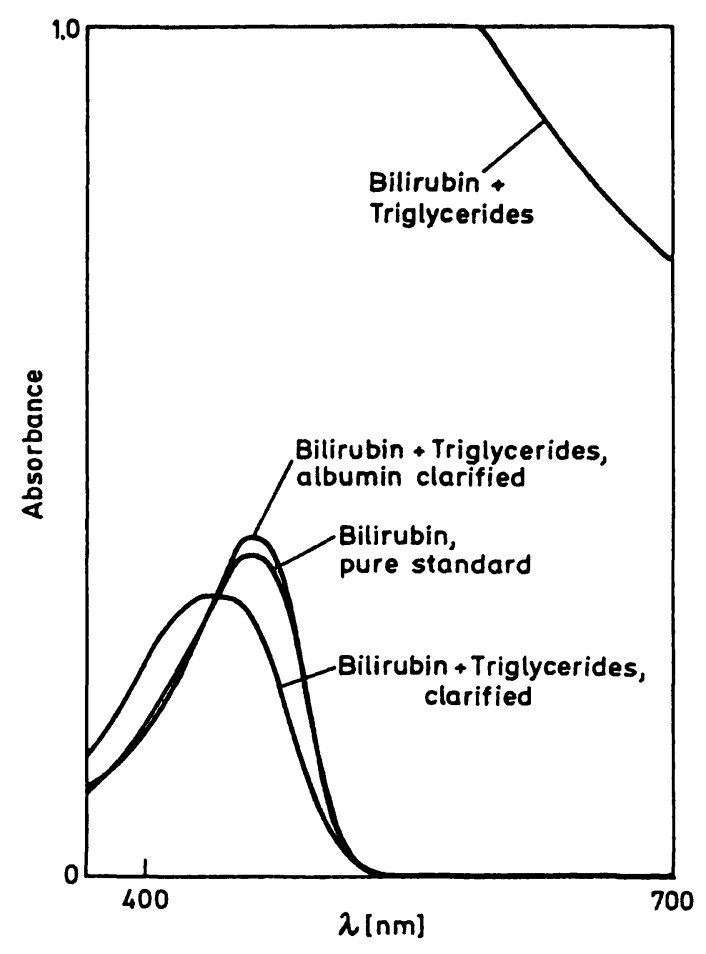

Fig. 1. The absorption spectrum of a pure bilirubin standard, and of an Intralipid-spiked bilirubin sample (final concentration bilirubin $=243 \mu \mathrm{mol} / \mathrm{l}$, Intralipid $=12$ $\mathrm{g} / \mathrm{l})$ shown as "Bilirubin + Triglycerides". The spiked sample when clarified with an albumin free enzymicclarifying reagent gave the spectrum "Bilirubin + Triglycerides, clarified" and "Bilirubin + Triglycerides, albumin clarified" when bovine serum albumin was included in the reagent.

tion ratio exceeds four. The lipolysis of Intralipid in the present clearing reaction may lead to a ratio as high as 200. Besides the in-vitro production of free fatty acids, serum samples obtained from patients undergoing fat infusions may contain appreciable amounts of fatty acids due to the in-vivo lipolysis of the fat emulsion (14).

The addition of more cyclodextrin to bind the interfering fatty acids led to the gradual formation of a new turbidity, apparently due to the precipitation of the fatty acid-cyclodextrin complex. For this reason a combination of albumin, a physiological fatty acid scavenger, and cyclodextrin was used to bind the excess free fatty acids, and prevent the spectral distortion of bilirubin as shown by the curve 'Bilirubin + Triglycerides, albumin clarified' in figure 1 . Neither scavenger was totally acceptable when used on its own. It should be noted here that the high concentration of bovine albumin may itself cause slight changes in the bilirubin-human albumin spectrum (fig. 2). The spectra of a human-based bilirubin standard in saline is shown as ' $\mathrm{A}$ '; in phosphate buffer, $\mathrm{pH} 8$, as ' $\mathrm{B}$ '; and in the enzymic-clarification reagent (containing

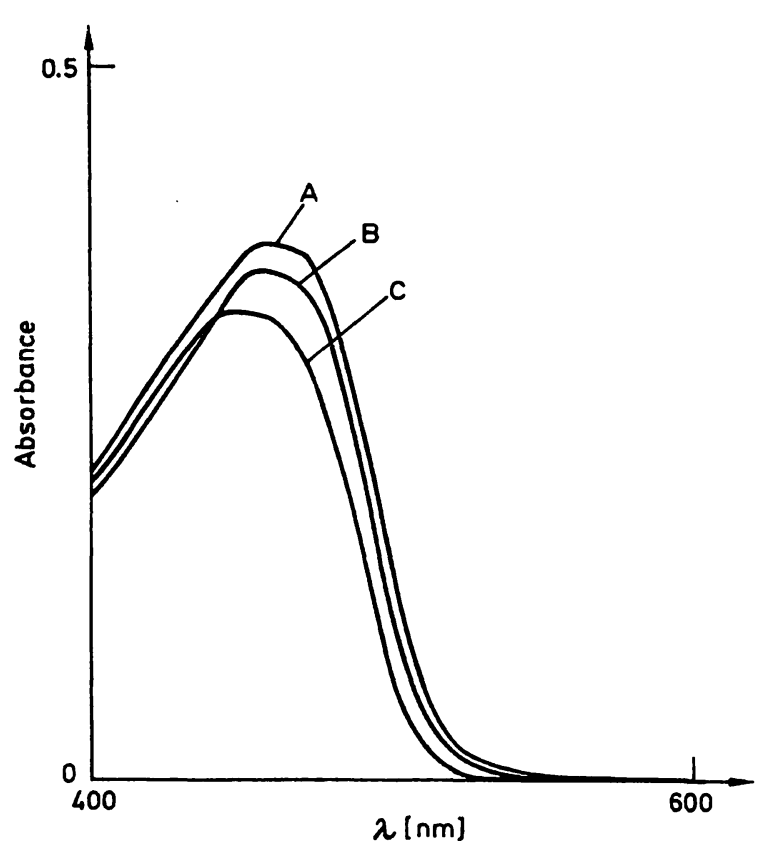

Fig. 2. 'A' represents the absorption spectrum of a bilirubin standard in saline; ' $B$ ' the spectrum in phosphate buffer, pH 8 and ' $C$ ' the spectrum in the enzymic-clarification reagent containing lipase, cyclodextrin and bovineserum albumin (bilirubin $=243 \mu \mathrm{mol} / \mathrm{l}$ ).

lipase, cyclodextrin and bovine serum albumin) as ' $\mathrm{C}$ '. It is apparent that there is a slight change in peak maximum and absorbance in the clarification reagent, however, because the same reagent is used for both calibration and testing this difference has no effect on the results. This is confirmed by our recovery data which indicate that the results are not significantly compromised (tab. 1).

Using the lipase-cyclodextrin-albumin reagent, clarification of samples containing Intralipid (as high as $16 \mathrm{~g} / 1$ triglyceride as intralipid) levels commonly achieved during infusions $(4,5)$ was rapid (less than 2 minutes) when the absorbance at $454 \mathrm{~nm}$ due to turbidity was monitored at room temperature and with a sample: reagent ratio of $1: 33$ as used in the Advanced Instrument test kit. The added albumin prevents the initially found spectral shift of the bilirubin-albumin complex (fig. 1), and also aids the scavenging of the released fatty acids, thus accelerating sample clarification. It is of note that incubation of the sample-reagent mixture at $37^{\circ} \mathrm{C}$ speeds the clearing process dramatically.

The enzyme clarification system is equally effective for a haemolysed lipaemic bilirubin sample (fig. 3). The Soret band and the mid-visible range peaks are distorted (Bilirubin $+\mathrm{Hb}+$ Triglycerides) in the turbid sample and converted to their correct absorbances (Bilirubin $+\mathrm{Hb}+$ Triglycerides, clarified) 
Tab. 1. Bilirubin quantitation in Intralipid-spiked neonatal sera on the BR II BILIRUBIN STAT ANALYSER ${ }^{a}$ )

\begin{tabular}{|c|c|c|c|c|c|c|}
\hline \multirow{2}{*}{$\begin{array}{l}\text { Intralipid } \\
\text { added } \\
(\mathrm{g} / \mathrm{l})\end{array}$} & \multicolumn{3}{|c|}{ Total bilirubin ( $\mu \mathrm{mol} / \mathrm{l})$} & \multicolumn{3}{|c|}{ Direct bilirubin ( $\mu \mathrm{mol} / \mathrm{l})$} \\
\hline & Theoretical & $\begin{array}{l}\text { Without } \\
\text { clarification }\end{array}$ & $\begin{array}{l}\text { With } \\
\text { clarification }\end{array}$ & Theoretical & $\begin{array}{l}\text { Without } \\
\text { clarification }\end{array}$ & $\begin{array}{l}\text { With } \\
\text { clarification }\end{array}$ \\
\hline 0 & - & 345 & 347 & - & 165 & 161 \\
\hline $\mathbf{0}$ & - & 35 & 36 & - & 12 & 14 \\
\hline 0 & - & 19 & 19 & - & $\overline{3}$ & 3 \\
\hline 0 & - & 94 & 99 & - & 54 & 50 \\
\hline $\mathbf{0}$ & - & 14 & 12 & - & 3 & 5 \\
\hline 0 & - & 125 & 125 & - & 57 & 54 \\
\hline 1.0 & 341 & 336 & 364 & 163 & 177 & 161 \\
\hline 2.0 & 19 & 61 & 17 & 3 & 3 & 5 \\
\hline 2.9 & 33 & 90 & 36 & 12 & 0 & 14 \\
\hline 3.9 & 90 & 153 & 101 & 52 & 31 & 47 \\
\hline 4.8 & 14 & 94 & 16 & 3 & 10 & 5 \\
\hline 9.1 & 113 & 161 & 121 & 52 & $*$ & 54 \\
\hline
\end{tabular}

a) Results shown as mean of duplicate analyses

* Could not be measured

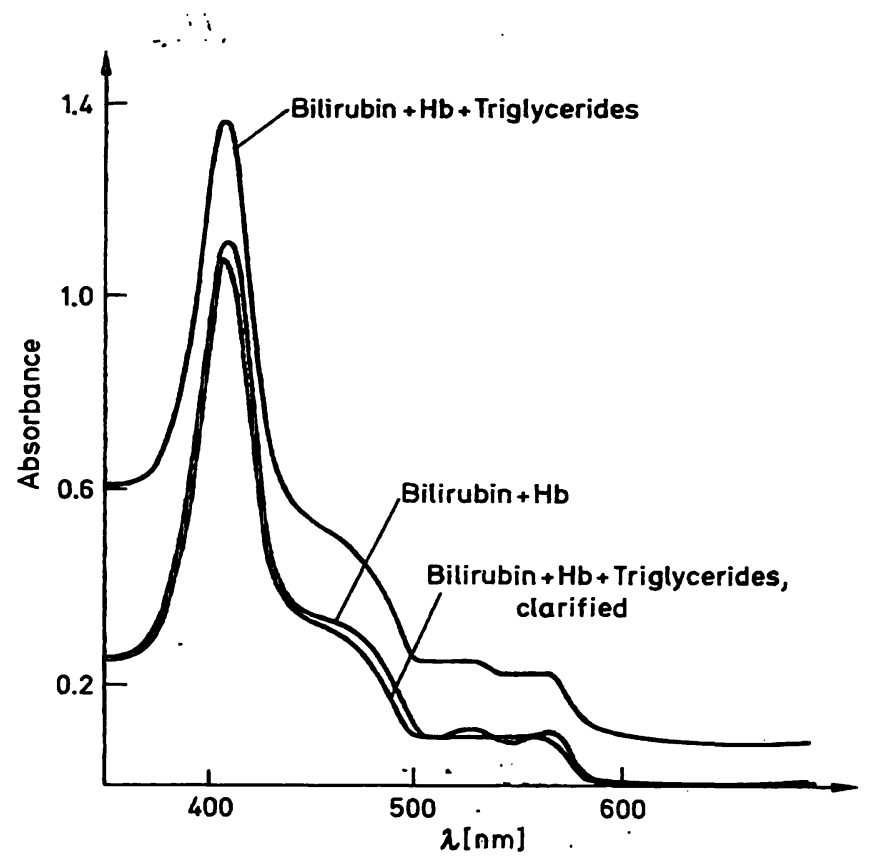

Fig. 3. "Bilirubin $+\mathrm{Hb}+$ Triglycerides" indicates the absorption spectrum of a bilirubin standard spiked with Intralipid and haemoglobin (final concentrations; triglycerides $1.2 \mathrm{~g} / \mathrm{l}$; bilirubin $=173 \mu \mathrm{mol} / \mathrm{l}$, haemoglobin $=$ $4.9 \mathrm{~g} / \mathrm{l})$. Clarification of this sample yields the spectrum "Bilirubin $+\mathrm{Hb}+$ Triglycerides, clarified" which closely approximates that of a haemolysed bilirubin sample "Bilirubin + $\mathrm{Hb}$ " containing the same concentration of bilirubin and haemoglobin as the lipaemic specimen.

when compared to the pure spectrum (Bilirubin + $\mathrm{Hb}$ ), within experimental error. This $171 \mu \mathrm{mol} / 1$ bilirubin standard contaminated with $4.9 \mathrm{~g} / 1$ haemoglobin and $1.2 \mathrm{~g} / \mathrm{l}$ triglyceride yielded 171 and $193 \mu \mathrm{mol} / 1$ bilirubin with and without clarification, respectively, when measured on the bilirubinometer.
The effect of total parenteral nutrition in samples assayed for bilirubin by the Bilirubin-Stat Analyzer is indicated in table 1 using Intralipid-spiked neonatal serums. It can be observed that the enzymic-clearing reagent has no detrimental effect on total and direct bilirubin assays in clear specimens $(0 \mathrm{~g} / 1$ Intralipid). Spurious bilirubin measurements begin in untreated specimens containing greater than $2 \mathrm{~g} / 1$ of Intralipid. When using the Bilirubinometer erroneous total bilirubin levels are apparently dependent upon the amount of fat emulsion present in the sample (tab. 2). In theory the apparent bilirubin concentration should increase with increasing triglyceride levels, therefore, the erratic nature of this interference is probably due to instrument design. Pretreatment of the specimen with the enzymic-clearing reagent avoids overestimation of the total bilirubin values. Direct bilirubin levels are also affected by the presence of lipaemia (tab. 1). In this case however, an increased or decreased value may be obtained suggesting an interference other than just turbidity. A similar variability of the effects of lipaemia on the formation of the

Tab. 2. Effect of the addition of Intralipid to total bilirubin values measured on the BR II BILIRUBIN STAT ANALYZER $^{\mathbf{a}}$ )

\begin{tabular}{|c|c|c|}
\hline \multirow{2}{*}{$\begin{array}{l}\text { Intralipid added } \\
(\mathrm{g} / \mathrm{l})\end{array}$} & \multicolumn{2}{|c|}{ Bilirubin $(\mu \mathrm{mol} / \mathrm{l})$} \\
\hline & $\begin{array}{l}\text { Without } \\
\text { clarification }\end{array}$ & $\begin{array}{l}\text { With } \\
\text { clarification }\end{array}$ \\
\hline $\begin{array}{c}0 \\
2.0 \\
5.0 \\
10.0 \\
12.5 \\
25.0\end{array}$ & $\begin{array}{r}173 \\
207 \\
214 \\
140 \\
77 \\
245\end{array}$ & $\begin{array}{l}176 \\
178 \\
179 \\
181 \\
179 \\
179\end{array}$ \\
\hline
\end{tabular}

a) results shown as mean of duplicate analyses 
azobilirubin colour has been reported by Chan et al. (6). However, as may be seen in this table, pretreatment of samples with the enzymic-clearing reagent eliminates these erroneous results.

Thus for accurate assessment of plasma bilirubin in infants on fat infusion therapy, appropriate corrections for lipaemia are important. Enzymic clarification is a simple, reliable and convenient solution to this problem. The routine use of the enzymic-clearing reagent eliminates the need for concern over the spectral aberrations due to iatrogenic hyperlipidaemia, and it has been demonstrated (7) that natural lipaemia may also be corrected by this procedure. It must be noted that the procedure has no effect on any volume displacement error caused by triglycerides which can become significant when triglyceride levels exceed $25 \mathrm{~g} / \mathrm{l}(15)$.

\section{References}

1. Creer, M. H. \& Ladenson, J. (1983) Lab. Med. 14, $351-355$.

2. Hindriks, F. R. \& Groen, A. (1978) Clin. Chem. 24, 2062-2063.

3. Miyada, D., Tipper, P., Jantsem, D., Simpkins, H., Steele, W. \& Flores, O. (1982) Clin. Biochem. 15, 185-188.

4. Moore, J. J., Sase, S. M. \& DeFranc, S. (1982) Clin. Chem. 28, 2334-2335.

5. Shennan, A. T., Cherian, A. G., Angel, A. \& Bryan M. H. (1976) J. Pediatr. 88, 285-288.

6. Chan, G., Merrils, K. \& Schiff, D. (1976) Clin. Biochem. 9, 96-98.

7. Sharma, A., Artiss, J. D., Strandbergh, D. R. \& Zak, B. (1985) Clin. Chim. Acta 147, 7-14.

8. Artiss, J. D., Strandbergh, D. R., Sharma, A. \& Zak, B. (1986) Clin. Chim. Acta 156, 151-156.

9. Malloy, H. T. \& Evelyn, K. A. (1937) J. Biol. Chem. 119, $481-490$.

10. Thiessen, H., Jacobsen, J. \& Brodersen, R. (1972) Acta Pediatr. Scand. 61, 258-288.

11. Jacobsen, J., Thiessen, H. \& Brodersen, R. (1971) Biochem. J. $126,7 \mathrm{P}$.

12. Starinsky, B. \& Shafrir, E. (1970) Clin. Chim. Acta 29, $311-318$.

13. Chan, G., Schiff, D. \& Stern, L. (1971) Clin. Biochem. 4, 208-215.

14. Reid, D. J. (1967) Br. J. Surg. 54, 198-207.

15. McGowan, M. W., Artiss, J. D. \& Zak, B. (1984) Anal. Biochem. 142, 239-251.

Joseph D. Artiss, Ph. D.

Dept. of Pathology

Gordon H. Scott Hall

of Basic Medical Sciences

540 East Canfield Avenue

Detroit, Michigan 48201

U.S. A. 
